\title{
Antibacterial activity of Hibiscus rosa-sinensis L. red flower against antibiotic-resistant strains of Helicobacter pylori and identification of the flower constituents
}

\author{
L.T.M. Ngan ${ }^{1 \oplus \bowtie}$, M.T. $\operatorname{Tan}^{1 \oplus}$, N.V.M. Hoang ${ }^{2 \odot}$, D.T. Thanh ${ }^{1,3 \odot}$, N.T.T. Linh ${ }^{4}$, T.T.H. Hoa ${ }^{5 \odot}$, \\ N.T.M. Nuong ${ }^{10}$, and T.T. Hieu ${ }^{10 \times}$ \\ ${ }^{1}$ Faculty of Biology and Biotechnology, VNUHCM-University of Science, Ho Chi Minh City, Vietnam \\ ${ }^{2}$ Oxford University Clinical Research Unit, Hospital for Tropical Diseases, Ho Chi Minh City, Vietnam \\ ${ }^{3}$ Faculty of Applied Sciences, Ton Duc Thang University, Ho Chi Minh City, Vietnam \\ ${ }^{4}$ Faculty of Chemistry, VNUHCM-University of Science, Ho Chi Minh City, Vietnam \\ ${ }^{5}$ Central Laboratory for Analysis, VNUHCM-University of Science, Ho Chi Minh City, Vietnam
}

\begin{abstract}
Utilization of plant resources for treatment of Helicobacter pylori infections is one of the appealing approaches as rapid emergence of antibiotic-resistant strains is occurring throughout the world. Ethanol extract and its fractions from Hibiscus rosa-sinensis red flower were assessed for antibacterial and urease inhibitory activities towards forty-three clinical strains and two reference strains of $H$. pylori. The ethyl acetate fraction exhibited the most potent bacteriostatic activity with minimum inhibitory concentrations (MICs) of $0.2-0.25 \mathrm{mg} / \mathrm{mL}$ and minimum bactericidal concentrations (MBCs) of $1.25-1.5 \mathrm{mg} / \mathrm{mL}$ against all test strains, including forty-three strains resistant to one to four antibiotics, azithromycin (MICs, $8-256 \mu \mathrm{g} / \mathrm{mL}$ ), erythromycin (MICs, 8-128 $\mu \mathrm{g} / \mathrm{mL}$ ), levofloxacin (MICs, 8-256 $\mu \mathrm{g} / \mathrm{mL}$ ), and/or metronidazole (MICs, 8-256 $\mu \mathrm{g} / \mathrm{mL}$ ). The fraction had similar antibacterial activities toward these test strains suggesting the preparation and the antibiotics do not have a common mechanism of anti- $H$. pylori activity. The fraction also had stronger effects on biofilm formation, morphological conversion, and urease activity of $\mathrm{H}$. pylori than the other fractions and the ethanol extract. These flower preparations were non-toxic to three human cell lines, and nine compounds were also isolated and identified from the ethyl acetate fraction. In vivo research needs to be conducted to confirm the potential usefulness of $H$. rosa-sinensis flower and its constituents for effective prevention and treatment of $H$. pylori disease.
\end{abstract}

Key words: Hibiscus rosa-sinensis flower; Antibacterial activity; Helicobacter pylori; Antibiotic resistance; Urease inhibition; Identified constituents

\section{Introduction}

Helicobacter pylori, a microaerobic, Gram-negative, and spiral-shaped bacterium, is known to be a major cause of gastrointestinal diseases such as chronic active gastritis, peptic ulcer, and gastric carcinoma (1). The global prevalence of $H$. pylori infection is about $51 \%$ in developing countries compared with $35 \%$ in developed countries (2). Since the infectious agent has been known to be a human carcinogenic factor, several antibiotic therapies have been prescribed to achieve high eradication rates. However, side-effects caused by the antibiotics and recurrence of the bacterial infection have made the therapies lose their effectiveness. In addition, widespread over-the-counter use of antibiotics in some developing countries has also contributed to the emergence of H. pylori antibiotic-resistant strains (3).

Folk medicinal plants, particularly their extracts and phytochemicals, have been perceived as relatively safe with little or no side effects and often act at multiple and novel target sites, thereby reducing the risk of resistance development (4). A number of medicinal plant preparations traditionally used for treatment of topical wounds and gastrointestinal disorders have been reported to have anti$H$. pylori activity $(5,6)$. Specifically, Hibiscus rosa-sinensis L. (Malvaceae family), a tropical evergreen shrub with red flowers, is traditionally used for the treatment of flu and cough, bronchitis, stomach pain, dysentery and diarrhea, 
and also for regulation of menstruation and stimulation of blood circulation (7). Aerial part extracts of the plant have been known to possess antiulcerogenic activity on gastric ulcers (8). Extracts from leaves and flowers of the plant have been proven to possess antibacterial activity $(9,10)$. Due to the effectiveness and safety, all parts of the plant could be used for pharmacological purposes $(11,12)$. The phytochemical constituents, pharmacological effects, and medicinal uses of the plant have been well described (13). In our previous study, the ethanol extract and ethyl acetate fraction derived from the $H$. rosa-sinensis flower were found to have antibacterial activity against $H$. pylori ATCC 43504 and four isolated compounds (naringenin, luteolin, myricetin, and protocatechuic acid) from the fraction were also proven to possess potent antibacterial properties against seven antibiotic-sensitive and -resistant strains of H. pylori (14).

The present study aims to report the antibacterial and urease inhibitory effects of crude ethanol extract of the $H$. rosa-sinensis red flower and its solvent-soluble fractions against forty-three clinical strains and two reference strains of $H$. pylori. In addition, isolation and structural elucidation of nine other compounds from the ethyl acetate fraction are also reported.

\section{Material and Methods}

The study was approved by the Ethical Committee of the Vietnam National University, Ho Chi Minh City (No. 702/DHQG-KHCN).

\section{Instrumental analyses}

${ }^{1} \mathrm{H}$ and ${ }^{13} \mathrm{C}$ NMR spectra were collected on a Bruker AVANCE III spectrometer (Germany) at 500 and $125 \mathrm{MHz}$, respectively, and chemical shifts are given in $\delta$ (ppm) using $\mathrm{CDCl}_{3}, \mathrm{CD}_{3} \mathrm{OD},\left(\mathrm{CD}_{3}\right)_{2} \mathrm{CO}$, or $\left(\mathrm{CD}_{3}\right)_{2} \mathrm{SO}$ as solvent. High-resolution mass spectrometry (HRMS) analysis was performed using a Bruker MicroTOF-QIl-system with an ESI-source. Melting point was determined using a Bibby Stuart Melting point SMB3 (UK). UV spectra were measured in ethanol on a T92 + Spectrophotometer (PG instrument, UK). Merck precoated silica gel plates (Kieselgel $60 \mathrm{~F}_{254}$, Germany) were used for analytical thin-layer chromatography (TLC). Merck preparative layer chromatography plates (PLC silica gel $60 \mathrm{~F}_{254}, 2 \mathrm{~mm}$ thickness) and Scharlau silica gel 60 (0.06-0.2 mm) (Spain) were used for isolation and purification.

\section{Materials}

The E test strips of six antibiotics (amoxicillin, azithromycin, erythromycin, levofloxacin, metronidazole, and tetracycline) were purchased from AB Biodisk (Sweden). Newborn bovine serum (NBS) was purchased from Hyclone (USA). Brucella broth (BB) and brain heart infusion $(\mathrm{BHI})$ broth were provided by Becton, Dickinson and Company (USA). All other chemicals and reagents used in this study were of analytical grade quality and available commercially.

\section{Plant material and preparation of extract and fractions}

The red flower petals of $H$. rosa-sinensis were collected in Binh Chanh district, Ho Chi Minh city, Vietnam $\left(10^{\circ} 43^{\prime} 21.7 " \mathrm{~N}, 106^{\circ} 40^{\prime} 06.1^{\prime \prime E}\right)$ in July 2019 . The species was identified by T.T. Hieu at Plant Biotechnology Laboratory, Department of Plant Biotechnology and Biotransformation, Faculty of Biology and Biotechnology, VNUHCM-University of Science, Ho Chi Minh City. A voucher specimen was deposited in the herbarium of the Department under the code HRS1001.

The flower ethanol (EtOH) extract and three solventsoluble fractions (hexane, ethyl acetate (EtOAc), and water fractions) were obtained as previously described (14). Briefly, the air-dried petals $(9.5 \mathrm{~kg})$ were pulverized and extracted 3 times with absolute ethanol to yield $1352 \mathrm{~g}$ of the EtOH extract, subsequently partitioned with hexane, EtOAc, and water by liquid fractionation to obtain $164 \mathrm{~g}$ hexane, $34 \mathrm{~g} \mathrm{EtOAc}$, and $1154 \mathrm{~g}$ water fractions. The extract and the fractions were subsequently tested against the forty-three clinical and two reference strains of $H$. pylori.

\section{Bacterial strains and culture conditions}

The two reference strains ATCC 43504 and ATCC 51932 and forty-three clinical strains of $H$. pylori were obtained in 2017 from the Microbiology Lab at OUCRU (Oxford University Clinical Research Unit, Vietnam). All bacterial strains were stored in $\mathrm{BHI}$ broth with $25 \%$ glycerol in a liquid nitrogen container and were cultured on Brucella agar supplemented with $10 \%$ NBS at $37^{\circ} \mathrm{C}$ for 3 days in a microaerophilic jar using Oxoid CampyGen gas packs (Thermo Scientific, UK).

\section{Human cell lines and cultures}

HeLa cells (ATCC CCL2, cervix carcinoma cell line), Jurkat cells (ATCC TIB-152, blood cancer cell line), and MCF7 (ATCC HTB-22, human breast cancer cell line) were provided from the American Type Culture Collection (USA). HeLa, Jurkat, and MCF7 cells used were between passages 4 and 20. These cell lines were cultured in Eagle's minimal essential medium (EMEM) supplemented with $10 \%$ fetal bovine serum (FBS), $2 \mathrm{mM}$ L-glutamine, $20 \mathrm{mM}$ HEPES, $0.025 \mu \mathrm{g} / \mathrm{mL}$ amphotericin B, $100 \mathrm{IU} / \mathrm{mL}$ penicillin, and $100 \mu \mathrm{g} / \mathrm{mL}$ streptomycin, at $37^{\circ} \mathrm{C}$ and $5 \%$ $\mathrm{CO}_{2}(14)$.

\section{Microbiological assay}

Minimum inhibitory concentrations (MICs) of the six antibiotics were determined by the $E$ test method according to the manufacturer's instructions. Different antibiotics (amoxicillin, azithromycin, erythromycin, levofloxacin, metronidazole, and tetracycline) served as positive controls. MICs, minimum bactericidal concentrations 
(MBCs), and time-killing of the extract and fractions towards all the bacterial strains were determined using broth microdilution assay.

For MICs, serial dilutions of concentrations ( 0.1 to $20 \mathrm{mg} / \mathrm{mL}$ ) of the extract and fractions were performed in $0.05 \mathrm{~mL}$ of $10 \%$ NBS-supplemented Brucella broth in sterile 96-well plates (15). The final concentration of DMSO in all assays was $2.5 \%$ or less. Subsequently, $0.05 \mathrm{~mL}$ of bacterial suspension $\left(\sim 5 \times 10^{6} \mathrm{CFU} / \mathrm{mL}\right)$ of each strain from cultures on Brucella agar was added to each well. The plates were then incubated at $37^{\circ} \mathrm{C}$ in microaerophilic jars and shaken at $50 \mathrm{rpm}$ for $48 \mathrm{~h}$. MICs are defined as the lowest concentrations that visibly inhibited bacterial growth using resazurin as an indicator. Negative controls contained the DMSO solution.

MBC values of the test materials were identified following the MIC assays and carried out in 24-well plates with Brucella agar medium (6). An amount of $0.01 \mathrm{~mL}$ of each well that retained the blue color of the indicator was taken and dropped onto the agar medium. The agar plates were incubated in microaerophilic jars at $37^{\circ} \mathrm{C}$ for $72 \mathrm{~h}$. The lowest concentrations, which exhibited no growth on the subculture, were determined as MBC values.

The time-killing assay was performed in sterile 96-well plates with the test compounds at concentrations of 1-6 times the MIC. Bacterial viability was measured after $0-48 \mathrm{~h}$ by a plate colony count technique as described previously (15). A control without the test compounds was also performed.

\section{Biofilm formation inhibitory assay}

Biofilm inhibition assay was performed in 96-well plates using crystal violet assay with the most active fraction at subMICs against $H$. pylori ATCC 43504 biofilm formation $48 \mathrm{~h}$ post-treatment as reported previously (14). Blank and background wells, which contained DMSO and the fraction, respectively, without bacterial suspension, were similarly prepared. After two days, staining with crystal violet was performed, and the biofilm formation was determined by measuring absorbance on a Microlisa Plus microplate reader (Micro Lab Instruments, India) at a wavelength of $595 \mathrm{~nm}$.

\section{Effect on morphology of $\boldsymbol{H}$. pylori}

H. pylori ATCC 43504 was cultured in Brucella broth with or without the extract or fractions at concentrations of 0.75 and $1.5 \mathrm{mg} / \mathrm{mL}$ under microaerophilic conditions for 24 and $48 \mathrm{~h}$. The bacterial suspension $(15 \mu \mathrm{L})$ was evenly spread and fixed on slides and then stained with $0.3 \%$ methylene blue solution. The proportion of coccoid vs spiral-shaped bacteria was determined using a EuromexBioBlue Lab microscope equipped with a Euromex camera (The Netherlands). Counts of 200 bacteria from each slide were done as reported previously (14).

\section{Cytotoxicity assay}

The cytotoxicity of the EtOH extract and fractions to HeLa, Jurkat, and MCF7 cells was evaluated using a sulforhodamine (SRB) assay described previously (14). In brief, cells were seeded onto 96-well plates at a density of $5 \times 10^{3}$ cells/well (HeLa), $5 \times 10^{4}$ cells/well (Jurkat), and $10^{4}$ cells/well (MCF7) for $24 \mathrm{~h}$. The culture medium was then removed from the wells and replaced with a medium containing various concentrations of the extract and fractions $(0-1 \mathrm{mg} / \mathrm{mL})$ in DMSO. After incubation for $48 \mathrm{~h}$, the cells were washed once with phosphate-buffered saline (PBS), fixed with cold trichloroacetic acid solution $(50 \% \mathrm{w} / \mathrm{v})$ for $20 \mathrm{~min}$, and stained with $0.2 \% \mathrm{SRB}$ for $20 \mathrm{~min}$. After gently washing five times with acetic acid solution (1\%), the protein-bound dye was solubilized in $10 \mathrm{mM}$ Tris base solution. Absorbance was read at $492 \mathrm{~nm}$ by the microplate reader. Camptothecin (Calbiochem, Germany) was used as a positive control.

\section{Inhibition of urease in vitro}

Inhibition of $H$. pylori ATCC 43504 urease was determined by measuring ammonia production in 96 -well plates using the salicylate-hypochlorite method with minor modification as described previously (14). In brief, the assay mixtures containing $0.25 \mu \mathrm{g}$ of urease crude $(0.04$ urease units) in $0.1 \mathrm{~mL}$ of the EDTA-sodium phosphate buffer $(\mathrm{pH} \mathrm{7.3)}$ and the extract and fractions at different concentrations $(0-5 \mathrm{mg} / \mathrm{mL})$ were preincubated at $37^{\circ} \mathrm{C}$ for 90 min with rotation at $50 \mathrm{rpm}$. An amount of $0.05 \mathrm{~mL}$ of urea solution $(10 \mathrm{mM})$ in the sodium phosphate buffer was added to each well, and the plates were incubated for $30 \mathrm{~min}$. Blank and background wells were similarly prepared but with inactive urease by heating at $100^{\circ} \mathrm{C}$ for $30 \mathrm{~min}$. Then, stop solutions including $0.035 \mathrm{~mL}$ of solution $\mathrm{A}(146 \% \mathrm{Na}$ salicylate $+0.1 \%$ sodium nitroprusside) and $0.065 \mathrm{~mL}$ of solution $\mathrm{B}(1.78 \% \mathrm{NaOH}+$ $11.57 \% \mathrm{Na}$ citrate $+0.54 \% \mathrm{NaOCl}$ ) were added in sequence. The ammonia released by the urease activity was quantified by measuring the absorbance on the microplate reader at $625 \mathrm{~nm}$. The protein content was determined using a Bradford protein assay kit (Biorad, USA). BSA was used as a protein standard. Thiourea served as a standard reference inhibitor. One unit of urease is defined as the amount of enzyme that releases $1 \mu \mathrm{M} \mathrm{NH}_{3}$ per minute, at $37^{\circ} \mathrm{C}, \mathrm{pH}=7.3$. Each treatment was performed in triplicate and repeated three times in independent experiments.

\section{Isolation of major compounds in the active fraction}

Due to being the most active fraction against the test $H$. pylori strains, the EtOAc fraction $(30 \mathrm{~g})$ was subjected to silica gel column chromatography and eluted with a gradient of hexane and EtOAc (100:0-0:100 by volume) described previously (14). In the present study, subfractions with similar $R_{f}$ values on TLC plates were pooled 
together, evaporated to dryness at $42^{\circ} \mathrm{C}$, and 40 subfractions were obtained. Repetitive silica gel column chromatography of the sub-fractions $E_{2}(219.4 \mathrm{mg}), E_{8}$ $(1370 \mathrm{mg}), \mathrm{E}_{11}(2180 \mathrm{mg}), \mathrm{E}_{12}(725.7 \mathrm{mg}), \mathrm{E}_{14}(1560 \mathrm{mg})$, $E_{21}(56.5 \mathrm{mg})$, and $E_{36}(425.3 \mathrm{mg})$ followed or not by plate chromatography resulted in nine compounds. The scheme of isolation of these compounds is presented in Figure S1.

\section{Statistical analyses}

MIC and MBC values of each test sample were results of at least three independent experiments. Antibacterial activity of the extract and fractions with MIC values $<0.1$, $0.1-0.62,>0.62-1.25,>1.25-2.5$, and $>2.5 \mathrm{mg} / \mathrm{mL}$ were defined as extremely high, high, moderate, low, and no growth inhibition, respectively (16). Cytotoxicity to human cell lines and urease inhibition activity are reported as $\mathrm{CC}_{50}\left(50 \%\right.$ cytotoxic concentration) and $\mathrm{IC}_{50}$ (concentration of half-maximal urease inhibition), respectively, and determined using GraphPad Prism 5 software program (USA). The $\mathrm{CC}_{50}$ and $\mathrm{IC}_{50}$ values of the treatments were considered to be significantly different if their $95 \%$ confidence intervals did not overlap. The Bonferroni method was used to test for multiple comparisons among the treatments. The percentage of biofilm inhibition (\%) was calculated as follows: $100-100 \times\left(O D_{\text {treatment }}-\right.$ $\left.O D_{\text {background }}\right) /\left(O D_{\text {control }}-O D_{\text {blank }}\right)$.

\section{Results}

\section{Antibiotic resistance of $\boldsymbol{H}$. pylori clinical strains}

The antibacterial activity of six common antibiotics toward forty-three $H$. pylori clinical isolates is shown in Figure 1 with MIC breakpoints for these test antibiotics (17-19). All the strains showed resistance to 1-4 test antibiotics. Four strains $(9.3 \%)$ were resistant to four antibiotics (azithromycin, erythromycin, levofloxacin, and metronidazole) with MICs of 8-256 $\mu \mathrm{g} / \mathrm{mL}$. Sixteen strains

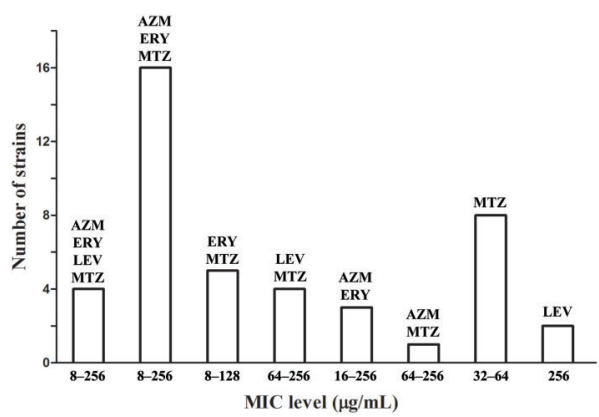

Figure 1. Antibiotic minimum inhibitory concentration (MIC) distribution for forty-three clinical strains of $H$. pylori using the $E$ test method. MIC breakpoints for azithromycin (AZM >1), erythromycin (ERY $>0.5)$, levofloxacin (LEV $>1)$, metronidazole (MTZ > 8), tetracycline $>1$, and amoxicillin $>0.5 \mu \mathrm{g} / \mathrm{mL}$ (refs. 17-19).
$(37.2 \%)$ were resistant to three antibiotics (azithromycin, erythromycin, and metronidazole) with MICs of 8-256 $\mu \mathrm{g} / \mathrm{mL}$. Thirteen strains $(30.2 \%)$ were resistant to two antibiotics (five strains to erythromycin and metronidazole with MICs of 8-128 $\mu \mathrm{g} / \mathrm{mL}$, four strains to levofloxacin and metronidazole with MICs of $64-256 \mu \mathrm{g} / \mathrm{mL}$, three strains to azithromycin and erythromycin with MICs of $16-256 \mu \mathrm{g} / \mathrm{mL}$, and one strain to azithromycin and metronidazole with MICs of 64-256 $\mu \mathrm{g} / \mathrm{mL})$. Ten strains $(23.3 \%$ ) were resistant to a single antibiotic (eight strains to metronidazole with MICs of 32-64 $\mu \mathrm{g} / \mathrm{mL}$ and two strains to levofloxacin with MICs of $256 \mu \mathrm{g} / \mathrm{mL}$ ). No strains showed resistance to amoxicillin and tetracycline. The reference strain ATCC 51932 was sensitive to all antibiotics, whereas strain ATCC 43504 showed resistance to metronidazole with a MIC of $32 \mu \mathrm{g} / \mathrm{mL}$.

\section{Growth inhibitory and bactericidal activities of $H$. rosa-sinensis flower}

The growth inhibitory and bactericidal activities of the extract and fractions toward the two reference strains and forty-three clinical strains are presented in Figure 2. Based on MIC values, EtOAc fraction had the highest level of growth-inhibitory activity $(0.2-0.25 \mathrm{mg} / \mathrm{mL})$, followed by the hexane fraction (moderate inhibition, $0.75-1.0 \mathrm{mg} / \mathrm{mL}$ ), and the EtOH extract (low inhibition, $1.25-1.75 \mathrm{mg} / \mathrm{mL}$ ). The water fraction showed very weak growth inhibitory activity.

Based on MBC values, the EtOAc fraction exerted the highest bactericidal activity $(1.25-1.5 \mathrm{mg} / \mathrm{mL})$, and the $\mathrm{EtOH}$ extract and hexane fraction did not show a significant difference in bactericidal activity $(5.0-7.5 \mathrm{mg} / \mathrm{mL})$. Noticeably, the EtOH extract and fractions were of similar growth-inhibiting activity and toxicity towards both antibiotic-susceptible and -resistant strains, although its concentrations were lower than those of the test antibiotics. The EtOAc fraction exhibited the most potency

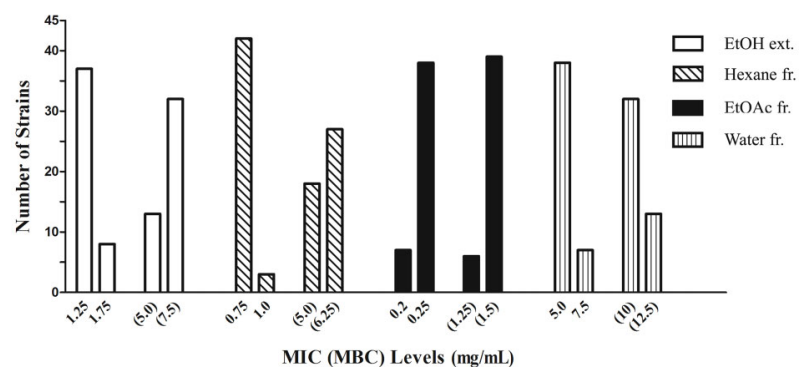

Figure 2. Minimum inhibitory concentrations (MIC) and minimum bactericidal concentrations (MBC, within parentheses) of $H$. rosasinensis ethanol extract (EtOH ext.) and three fractions (fr.) (Hexane fr., ethyl acetate (EtOAc) fr., and Water fr.) for forty-three clinical and two reference strains of $H$. pylori using broth dilution bioassay. 
against all forty-three clinical strains of $H$. pylori resistant to 1-4 test antibiotics, and two reference strains, ATCC 43504 resistant to metronidazole and ATCC 51932 susceptible to all the six test antibiotics.

The time course of bactericidal activity of EtOAc fraction at various concentrations of $1(0.25 \mathrm{mg} / \mathrm{mL})$, $2(0.5 \mathrm{mg} / \mathrm{mL}), 4(1 \mathrm{mg} / \mathrm{mL}), 5(1.25 \mathrm{mg} / \mathrm{mL})$, and $6(1.5$ $\mathrm{mg} / \mathrm{mL}$ ) times the MIC toward $H$. pylori ATCC 43504 was likewise investigated and is reported in Figure 3 . The results indicated that the viable count of the bacteria was reduced in a dose-dependent manner. Treatment of $H$. pylori with EtOAc fraction at the six and five times MIC reduced the viability of $H$. pylori by $\sim 6.1 \log _{10}$ and $3.7 \log _{10}$ at 24 and $12 \mathrm{~h}$, respectively; at the four times and twice MIC resulted in $\sim 4.1 \log _{10}$ and $\sim 2.2 \log _{10}$ reduction at 36 and $18 \mathrm{~h}$, respectively. The EtOAc fraction completely killed all the bacteria $36 \mathrm{~h}$ post-treatment at MBC (six times MIC). This indicated that the EtOAc fraction exhibited bacteriostatic activity toward all test $H$. pylori strains rather than bactericidal effect. Bactericidal activity of a plant preparation significantly depends on type of the extract and its components, concentration, and exposure time, as well as density of test bacterial strains.

\section{Anti-biofilm formation activity}

Our results of antibiofilm formation showed that EtOAc fraction at subMICs inhibited biofilm formation of $H$. pylori ATCC 43504 (Figure 4). The EtOH extract and the other two fractions did not exhibit an antibiofilm effect on the strain at all test concentrations. At concentration of $1 / 2 \times$ MIC $(0.125 \mathrm{mg} / \mathrm{mL}), 1 / 4 \times \mathrm{MIC}$, and $1 / 8 \times \mathrm{MIC}$, EtOAC fraction produced significant antibiofilm activity and reduced biofilm formation by $79.3,56.4$, and $44.8 \%$, respectively $(\mathrm{P}<0.05)$, while at $1 / 16 \mathrm{MIC}$ and $1 / 32 \mathrm{MIC}$, the fraction showed weak antibiofilm activity with no significant difference $(P>0.05)$.

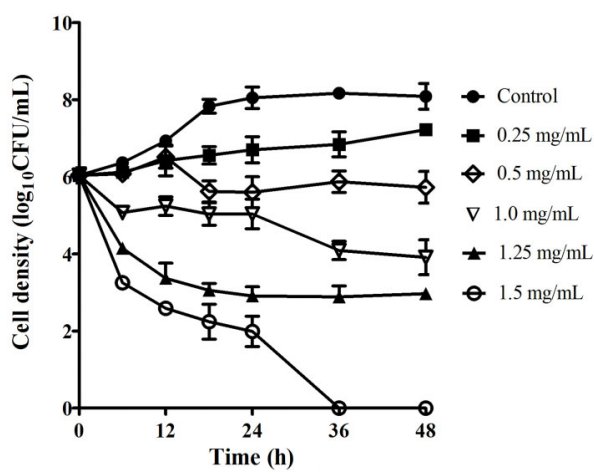

Figure 3. Time-course bactericidal activity of ethyl acetate (EtOAc) fraction at different concentrations ranging from minimum inhibitory concentration ( $\mathrm{MIC}=0.25 \mathrm{mg} / \mathrm{mL}$ ) to minimum bactericidal concentration $(\mathrm{MBC}=1.5 \mathrm{mg} / \mathrm{mL}$ ) toward $H$. pylori ATCC 43504. Data are reported as means \pm SE.

\section{Effect on morphology of $\boldsymbol{H}$. pylori}

The proportion of coccoid versus spiral form of H. pylori ATCC 43504 was recorded at 0.75 and $1.5 \mathrm{mg} / \mathrm{mL}$ of the $\mathrm{EtOH}$ extract and fractions after 24 or $48 \mathrm{~h}$ treatment (Figure 5). Effect of concentration ( $F=1484.86$; $d f=8,45$; $\mathrm{P}<0.0001)$ and exposure time $(\mathrm{F}=1092.21 ; \mathrm{df}=1,45$; $\mathrm{P}<0.0001$ ) on conversion of $H$. pylori to the coccoid form was significant. The concentration by exposure interaction was also significant $(F=215.56 ; d f=8,45 ; P<0.0001)$. The EtOAc fraction caused considerable conversion to the coccoid forms (91 vs $18 \%$ at 1.5 and $0.75 \mathrm{mg} / \mathrm{mL}$ after $48 \mathrm{~h}$ of treatment). The hexane fraction caused higher conversion to the coccoid forms than the $\mathrm{EtOH}$ extract at

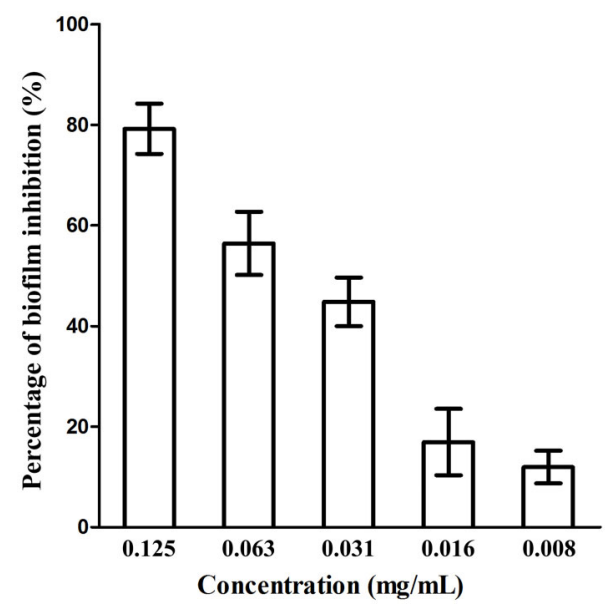

Figure 4. Effect of ethyl acetate (EtOAc) fraction at concentrations of subminimum inhibitory concentrations (MICs) on $\mathrm{H}$. pylori ATCC 43504 biofilm formation $48 \mathrm{~h}$ post-treatment. Data are reported as means \pm SD.

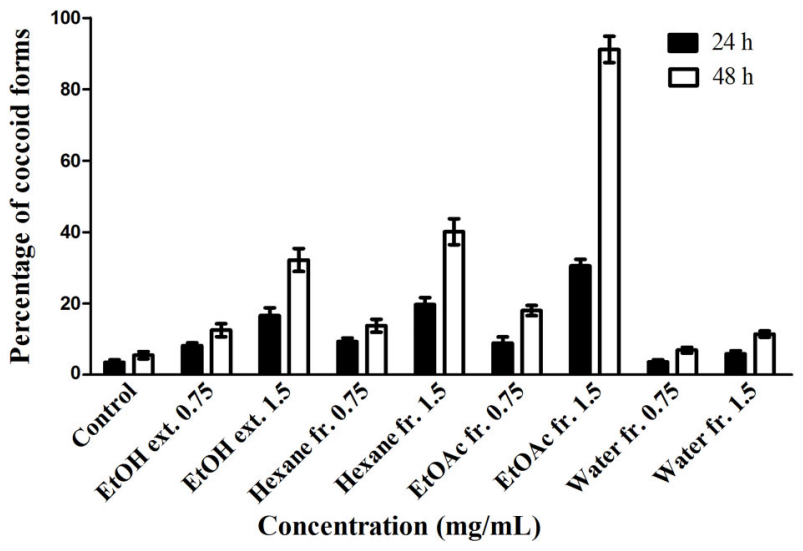

Figure 5. Effect of $H$. rosa-sinensis flower ethanol extract (EtOH ext.), and its fractions (Hexane fr., ethyl acetate (EtOAc) fr., and Water fr.) at concentrations of 0.75 and $1.5 \mathrm{mg} / \mathrm{mL}$ on $H$. pylori ATCC 43504 morphology 24 and $48 \mathrm{~h}$ post-treatment. Data are reported as means \pm SD. 
$1.5 \mathrm{mg} / \mathrm{mL}$ (40.1 and $32.2 \%$, respectively, $\mathrm{P}<0.001)$, while the hexane fraction and $\mathrm{EtOH}$ extract at $0.75 \mathrm{mg} /$ $\mathrm{mL}$ did not produce a significant difference in the coccoid conversion $(P>0.05)$. The water fraction caused the lowest conversion $(11.4 \%$ at $1.5 \mathrm{mg} / \mathrm{mL})$, and the proportion of conversion caused by the water fraction at $0.75 \mathrm{mg} / \mathrm{mL}$ was not significantly different from that of the control group $(P>0.05)$.

\section{Cytotoxicity}

In order to determine the selectivity of the anti-H. pylori activity, the cytotoxic effects of the red flower preparations were examined (Table 1). The EtOH extract, hexane, EtOAc, and water fractions displayed no significant cytotoxicity with $\mathrm{CC}_{50}>1,0.646-0.878,0.339-0.445$, and $>1 \mathrm{mg} / \mathrm{mL}$, respectively, towards HeLa, Jurkat, and MRF7 cell lines, compared with that of the positive control camptothecin with $\mathrm{CC}_{50}$ of $0.005-0.81 \mu \mathrm{g} / \mathrm{mL}$ $(P<0.001)$.

\section{Urease inhibitory activity}

The flower EtOH extract and fractions inhibited the activity of $H$. pylori urease (Table 2). The EtOAc fraction exhibited the highest activity $\left(\mathrm{IC}_{50}\right.$ at $\left.0.101 \mathrm{mg} / \mathrm{mL}\right)$, caused a steep dose-response curve of percentage of urease inhibition, and complete inhibition at $0.3 \mathrm{mg} / \mathrm{mL}$, followed by the water fraction with lower urease inhibitory activity (Figure 6). The EtOH extract and hexane fraction produced weak and no inhibition to $H$. pylori urease, respectively. However, the extract and fractions showed a lower effect than the positive control thiourea $\left(\mathrm{IC}_{50}\right.$ at $0.044 \mathrm{mg} / \mathrm{mL}$ ) (Table 2).

\section{Identification of major compounds in EtOAc fraction derived from $\boldsymbol{H}$. rosa-sinensis flower}

Nine compounds from the active EtOAc fraction were obtained and identified based on melting points and spectral data such as ESI-HRMS, ${ }^{1} \mathrm{H}-\mathrm{NMR},{ }^{13} \mathrm{C}-\mathrm{NMR}$, 2D ${ }^{1} \mathrm{H}^{-13} \mathrm{C} \mathrm{HSQC}$, and 2D ${ }^{1} \mathrm{H}_{-}{ }^{13} \mathrm{C} \mathrm{HMBC}$. These nine compounds isolated and identified in this study can be found in several plant species, and three compounds (taraxerol acetate (20), p-hydroxybenzoic acid (21), and quercetin (21)) were previously identified in $H$. rosasinensis. The remaining six compounds are being reported here for the first time in $H$. rosa-sinensis red flower. The structure of these identified compounds (Figure 7) were determined and further compared with the reported literature, and are in agreement with taraxerol acetate (compound 1) $\left(\mathrm{C}_{32} \mathrm{H}_{52} \mathrm{O}_{2}\right.$, ESI-HRMS, m/z 469.4032 [M + $\mathrm{H}^{+}$) (20), 5-hydroxy-7,4'-dimethoxyflavone (compound 2) $\left(\mathrm{C}_{17} \mathrm{H}_{14} \mathrm{O}_{5}\right.$, ESI-HRMS, $\left.\mathrm{m} / \mathrm{z} 299.0963[\mathrm{M}+\mathrm{H}]^{+}\right)(22)$,

Table 2. Concentration of half-maximal inhibition $\left(\mathrm{IC}_{50}\right)$ of $\mathrm{H}$. rosasinensis flower ethanol $(\mathrm{EtOH})$ extract, fractions, and thiourea on H. pylori ATCC 43504 urease inhibition.

\begin{tabular}{lcc}
\hline Sample & Slope $\pm \mathrm{SE}$ & $\mathrm{IC}_{50}, \mathrm{mg} / \mathrm{mL}(95 \% \mathrm{Cl})$ \\
\hline EtOH extract & $2.304 \pm 0.096$ & $2.144(2.100-2.190)$ \\
Hexane fraction & - & - \\
EtOAc fraction & $2.203 \pm 0.039$ & $0.101(0.100-0.107)$ \\
Water fraction & $1.875 \pm 0.064$ & $0.431(0.415-0.447)$ \\
Thiourea & $1.861 \pm 0.107$ & $0.044(0.042-0.047)$ \\
\hline
\end{tabular}

Cl: confidence interval; -: no inhibition; EtOAc: ethyl acetate.

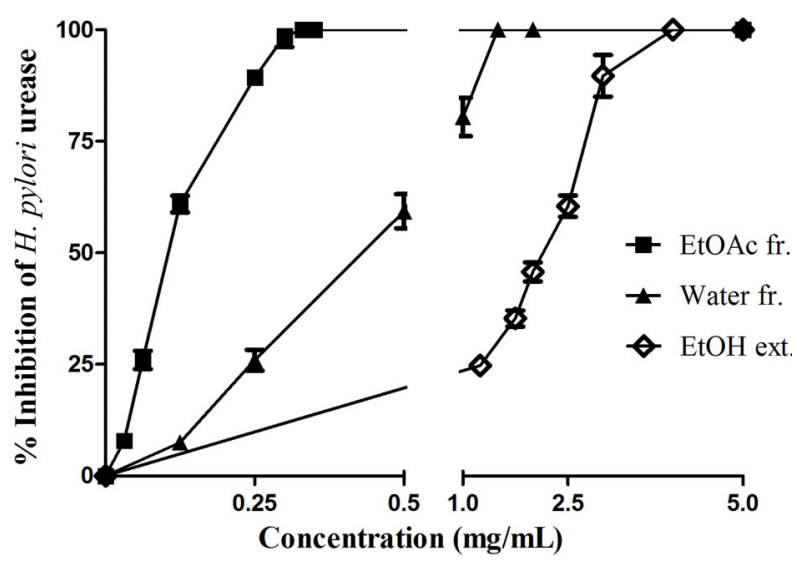

Figure 6. $H$. pylori urease inhibitory activity of $H$. rosa-sinensis flower ethanol extract (EtOH ext.) and two fractions (fr.) (ethyl acetate (EtOAc) fr. and Water fr.). Data are reported as means \pm $\mathrm{SD}$.

Table 1. Cytotoxic effect (50\% cytotoxic concentration, $\left.\mathrm{CC}_{50}\right)$ of $H$. rosa-sinensis flower ethanol $(\mathrm{EtOH})$ extract and fractions on three human cell lines.

\begin{tabular}{lccc}
\hline Sample & \multicolumn{3}{c}{$\mathrm{CC}_{50}, \mathrm{mg} / \mathrm{mL}(95 \% \mathrm{Cl})$} \\
\cline { 2 - 4 } & HeLa & Jurkat & MCF7 \\
\hline EtOH extract & $>1$ & $>1$ & $>1$ \\
Hexane fraction & $0.878(0.817-0.944)$ & $0.646(0.626-0.666)$ & $0.801(0.785-0.817)$ \\
EtOAc fraction & $0.445(0.421-0.471)$ & $0.363(0.302-0.436)$ & $0.339(0.314-0.366)$ \\
Water fraction & $>1$ & $>1$ & $>1$ \\
Camptothecin $(\mu \mathrm{g} / \mathrm{mL})$ & $0.810(0.704-0.932)$ & $0.005(0.004-0.006)$ & $0.005(0.004-0.006)$ \\
\hline
\end{tabular}

Cl: confidence interval; EtOAc: ethyl acetate. 
<smiles>CC(=O)OC1CCC2(C)C(CCC3(C)C4=CCC5(C)CCC(C)(C)CC5C4(C)CCC32C)C1(C)C</smiles><smiles>COc1ccccc1OCC(C)CO</smiles>

4) Guaifenesin

1) Taraxerol acetate<smiles>COc1ccc(-c2cc(=O)c3c(O)cc(OC)cc3o2)cc1</smiles><smiles>Cc1ccc(/C=C/C(=O)O)cc1</smiles>

5) trans-p-Coumaric acid<smiles>COc1cc(O)c2c(=O)cc(-c3ccc(O)c(OC)c3)oc2c1</smiles><smiles>O=C(O)c1ccc(O)cc1</smiles>

6) p-Hydroxybenzoic acid

3) Velutin<smiles>O=c1c(O)c(-c2ccc(O)c(O)c2)oc2cc(O)cc(O)c12</smiles><smiles>C=C(c1ccc(C)cc1)c1ccc(CO)o1</smiles>

8) Quercetin

9) Fumaric acid

Figure 7. Chemical structures of nine compounds identified from ethyl acetate (EtOAc) fraction derived from $\mathrm{H}$. rosa-sinensis flower extract.

velutin (compound 3) $\left(\mathrm{C}_{17} \mathrm{H}_{14} \mathrm{O}_{6}\right.$, ESI-HRMS, $\mathrm{m} / \mathrm{z} 315$. $\left.0850[\mathrm{M}+\mathrm{H}]^{+}\right)(23)$, guaifenesin (compound 4) $\left(\mathrm{C}_{10} \mathrm{H}_{14} \mathrm{O}_{4}\right.$, ESI-HRMS, $\left.\mathrm{m} / \mathrm{z} 221.0818[\mathrm{M}+\mathrm{Na}]^{+}\right)(24)$, trans-p-coumaric acid (compound 5) $\left(\mathrm{C}_{9} \mathrm{H}_{8} \mathrm{O}_{3}, \mathrm{ESI}-\right.$ HRMS, m/z 163.0356 [M - H] ) (25), p-hydroxybenzoic acid (compound 6$)\left(\mathrm{C}_{7} \mathrm{H}_{6} \mathrm{O}_{3}\right.$, ESI-HRMS, $\mathrm{m} / \mathrm{z} 137.0219$ $\left.[\mathrm{M}-\mathrm{H}]^{-}\right)$, 5-hydroxymethylfurfural (compound 7) $\left(\mathrm{C}_{6} \mathrm{H}_{6} \mathrm{O}_{3}\right)$, quercetin (compound 8) $\left(\mathrm{C}_{15} \mathrm{H}_{10} \mathrm{O}_{7}\right.$, ESI-HRMS, $\mathrm{m} / \mathrm{z}$ $303.0499\left[\mathrm{M}+\mathrm{H}^{+}\right)(25)$, and fumaric acid (compound 9) $\left(\mathrm{C}_{4} \mathrm{H}_{4} \mathrm{O}_{4}\right.$, ESI-HRMS, m/z $\left.115.0029[\mathrm{M}-\mathrm{H}]^{-}\right) .{ }^{1} \mathrm{H}-\mathrm{NMR}$, ${ }^{13} \mathrm{C}-\mathrm{NMR}$, and $\mathrm{HMBC}$ data of the nine compounds isolated from $H$. rosa-sinensis flower are shown in Table S1 and Figure S2.

\section{Discussion}

In recent years, the increasing resistance of $H$. pylori to several common antibiotics has significantly decreased the efficacy of treatment and drawn global attention. Plant extracts and phytochemicals derived from medicinal plants have proven to be antibacterial agents and some of them have multiple functions and act at multiple target sites (4). Various extracts from all parts of $H$. rosa-sinensis have been reported to exhibit a wide range of beneficial effects such as hypotensive, antipyretic, anti-inflammatory, anticancer, antioxidant, antidiabetic, and antibacterial activities $(8,10,13)$. Flower extracts of $H$. rosa-sinensis were suggested as an alternative source of antibacterial agent against human pathogens (10) and possess stronger antibacterial activity than that of the leaf against some clinical bacterial isolates, such as Staphylococcus aureus, Proteus vulgaris, Pseudomonas aeruginosa, and Citrobacter sp. (9). Methanol and hexane extracts of the flower have strong antigrowth activities against Bacillus subtilis and Escherichia coli, while ethanol extract shows strong inhibition against Salmonella spp. (10). In a study of 
medicinal plants traditionally used for gastrointestinal disorders, leaf and stem extracts from a white flower variety of $H$. rosa-sinensis exhibit moderate and low activity against metronidazole-resistant clinical isolates of $H$. pylori, respectively (5). In the present study, EtOH extract and fractions from the red flower of $H$. rosasinensis were proven to have antibacterial activities against both antibiotic-susceptible and -resistant strains of $H$. pylori, although its concentrations were lower than those of the test antibiotics. The EtOAc fraction exhibited the most potency against all forty-three clinical strains of $H$. pylori resistant to 1-4 test antibiotics, and two reference strains ATCC 43504 resistant to metronidazole and ATCC 51932 susceptible to all the six test antibiotics.

Numerous extracts from medicinal plants also possess antibacterial activity against antibiotic-resistant strains of $H$. pylori. Methanol extract from young stems of Terminalia spinosa shows strong antibacterial activity toward 12 strains of $H$. pylori (26). Natural almond skin polyphenolrich extract has an inhibitory effect against two clarithromycin-resistant strains of $H$. pylori (27). Hexane and chloroform fractions from leaves of Magnolia sieboldii display strong growth inhibition to the strain ATCC 43504 (28). Ethanol extracts of Ampelopsis cantoniensis and Cleistocalyx operculatus display similar anti-H. pylori activity against two antibiotic-resistant clinical isolates (6). In the present study, the EtOAc fraction of $H$. rosasinensis flower significantly reduced the viability of $H$. pylori ATCC 43504 at 2, 4, and $5 \times$ MIC after 12-36 h of incubation, and only completely killed the strain at $6 \times \mathrm{MIC}(\mathrm{MBC}) 36 \mathrm{~h}$ post-treatment. This indicated that the EtOAc fraction exhibited bacteriostatic activity toward all test $H$. pylori strains rather than bactericidal effect. Bactericidal activity of a plant preparation significantly depends on the type of the extract and its components, concentration, and exposure time, as well as density of test bacterial strains. In our previous study, four compounds (naringenin, luteolin, myricetin, and protocatechuic acid) identified from the EtOAc fraction of $H$. rosa-sinensis red flower were also found to be bacteriostatic rather than bactericidal against $H$. pylori ATCC 43504 (14).

In addition, inhibitory effects of antibacterial agents against biofilm formation play a major role in the eradication of $H$. pylori infection. Methanol extract from calyces of $H$. sabdariffa was reported to have fungistatic effect against Candida albicans and significantly reduces biofilm formation of six strains of fluconazole resistant C. albicans at subMIC (1/2 and 1/4 MIC) (29). Our present study also demonstrated that the EtOAc fraction of $H$. rosa-sinensis red flower exhibited the potential inhibitory effect on $H$. pylori biofilm formation at subMIC (1/2, $1 / 4$, and $1 / 8 \times \mathrm{MIC})$. Moreover, morphological conversion of the $H$. pylori cells from spiral to coccoid forms caused by plant preparations is one possible mechanism affecting the survival and colonization of the bacterium on the gastric mucosa. Methyl gallate, paeonol, and 1,2,3,4,6penta-O-galloyl- $\beta$-D-glucopyranose from the root extract of $P$. lactiflora were reported to cause $91-74 \%$ coccoid conversion at $2 \times \mathrm{MIC}$ after $48 \mathrm{~h}$ of treatment (16). In the present study, the EtOAc fraction from the flower extract of $H$. rosa-sinensis caused considerable conversion to the coccoid forms (91\% at MBC after $48 \mathrm{~h}$ of treatments).

$H$. pylori urease also plays a crucial role in colonization and pathogenesis of the pathogen in the stomach. Hence, inhibition of the enzyme activity is one of the most important strategies for the treatment of the bacterial infection. Several plant preparations have been reported to possess multiple effects toward the metabolic activities of $H$. pylori. Extracts from Camellia sinensis were found to inhibit the bacterial growth and the function and production of urease (30). Acetone, aqueous, and methanol extracts of Acacia nilotica, Adhatoda vasica, Calotropis procera, Casuarina equisetifolia, and Fagoniaar abica traditionally used in folk medicine for the treatment of a variety of common ailments in Pakistan were reported to have antiurease activity (31). Epigallocatechin gallate (EGCG) from the green tea plant inhibits the urease activity and motility of $H$. pylori (32). In the present study, the EtOAc fraction derived from $H$. rosa-sinensis flower exhibited the highest activity, followed by the water fraction with lower urease inhibitory activity.

Conversion of the spiral to the coccoid forms in $H$. pylori is caused by environmental factors, antibiotics (33), and phytochemicals (16). It has been suggested that coccoid forms consist of viable but non-culturable coccoid (VBNC) and non-viable degenerative coccoid forms (34). The VBNC form has minimal metabolic activity and can survive during stress conditions such as in the presence of antibiotics, which may be one of the causes of treatment failure (35). However, potent plant preparations that act through multiple mechanisms on the bacterium and could be consumed for long-term treatment due to their safety may successfully kill the bacterium including the dormant form. In the present study, the EtOAc fraction of $H$. rosasinensis inhibited the growth, biofilm, and urease activities of $H$. pylori. These promising effects may contribute to combat resistance and prevent recurrence of $H$. pylori. The EtOH extract, hexane, EtOAc, and water fractions of the flower showed no significant cytotoxicity towards the three cell lines (HeLa, Jurkat, and MRF7). This suggested that their anti-H. pylori activities might not be due to general toxicity. Previously, $H$. rosa-sinensis plant and its chemical constituents were suggested to be utilized in pharmacological applications because extracts of the flower and the leaf were considered relatively safe $(11,12)$.

The phytochemical constituents, pharmacological effects, and medicinal uses of $H$. rosa-sinensis have been well described and the main bioactive compounds responsible for its medicinal effects are namely flavonoids, tannins, terpenoids, saponins, and alkaloids (13). Among the identified compounds shown in Figure 7, compound 2 
(5-hydroxy-7,4'-dimethoxyflavone) was active against C. albicans with a mechanism of action including inhibition of $C$. albicans' ergosterol synthesis, drug efflux pumps, and antioxidant enzymes (22). Compound 3 (velutin) (23), compound 5 (trans-p-coumaric acid) (36), and compound 6 (p-hydroxybenzoic acid) (37) exhibited significant dosedependent activity against both Gram-negative and -positive pathogenic bacteria, such as Vibrio cholera, Salmonella Typhimurium, Shigella dysenteriae, E. coli, Pseudomonas aeruginosa, Streptococcus pneumonia, S. mutans, Staphylococcus aureus, and Bacillus subtilis. Compound 8 (quercetin) exhibited inhibitory effect on biofilm formation by $S$. mutans (38) and inhibited $H$. pylori urease activity (39).

Among the three flavonoids (naringenin, myricetin, and luteolin) derived from the EtOAc fraction of $H$. rosasinensis red flower, naringenin was reported to have the most growth-inhibiting and antibiofilm activities and induced morphological transformation of $H$. pylori (14). In our present study, the EtOAc fraction exerted lower inhibitory activity than the positive control thiourea against $H$. pylori urease. However, myricetin and luteolin were found to exhibit stronger inhibitory activity than the positive control (14). It was reported that plant flavonoids may contribute to several antimicrobial mechanisms, such as inhibition of nucleic acid synthesis (by inhibiting helicase, gyrase, and topoisomerase activity), disruption of membrane function (by inhibiting efflux pumps, porins, fatty

\section{References}

1. Atherton JC, Blaser MJ. Coadaptation of Helicobacter pylori and humans: Ancient history, modern implications. J Clin Invest 2009; 119: 2475-2487, doi: 10.1172/JCI38605.

2. Zamani M, Ebrahimtabar F, Zamani V, Miller WH, Alizadeh-Navaei R, Shokri-Shirvani J, Derakhshan MH. Systematic review with meta-analysis: the worldwide prevalence of Helicobacter pylori infection. Aliment Pharm Ther 2018; 47:868-76, doi: 10.1111/apt.14561.

3. Binh TT, Shiota S, Nguyen LT, Ho DD, Hoang HH, Ta L, et al. The incidence of primary antibiotic resistance of Helicobacter pylori in Vietnam. J Clin Gastroenterol 2013; 47: 233238, doi: 10.1097/MCG.0b013e3182676e2b.

4. Raskin I, Ribnicky DM, Komarnytsky S, llic N, Poulev A, Borisjuk N, et al. Plants and human health in the twenty-first century. Trends Biotechnol 2002; 20: 522-531, doi: 10.1016/ S0167-7799(02)02080-2.

5. Uyub AM, Nwachukwu IN, Azlan AA, Fariza SS. In-vitro antibacterial activity and cytotoxicity of selected medicinal plant extracts from Penang Island Malaysia on metronidazole-resistant-Helicobacter pylori and some pathogenic bacteria. Ethnobot Res Appl 2010; 8: 95-106, doi: 10.17348/era.8.0.95-106.

6. Ngan LTM, Dung PP, Nhi NVTY, Hoang NVM, Hieu TT. Antibacterial activity of ethanolic extracts of some Vietnamese medicinal plants against Helicobacter pylori. AIP Confer Proceed 2017; 1878: 020030, doi: 10.1063/1.5000198. acid synthase, and peptidoglycan synthesis), inhibition of energy metabolism, quorum sensing and biofilm formation, and thereby attenuation of the pathogenicity (40). These isolated compounds in the present study may serve as the lead compounds for development of new antipathogenic agents, a critical requirement to counteract the antibiotic-resistant bacteria.

In this work, these results demonstrated that the EtOAc fraction derived from red flower extract of $H$. rosasinensis was highly bacteriostatic against both antibioticsusceptible and -resistant strains of $H$. pylori through potent effects on biofilm formation, morphological conversion, and urease activity of $H$. pylori. The results suggested that the EtOAc fraction and its isolated compounds could have great potential as new, effective, and safe agents for the prevention or treatment of $H$. pylori infection.

\section{Supplementary Material}

Click to view [pdf].

\section{Acknowledgments}

This work was funded by the Vietnam National Foundation for Science and Technology Development (NAFOSTED) under grant number 106-YS.06-2015.17.

7. Jadhav VM, Thorat RM, Kadam VJ, Sathe NS. Traditional medicinal uses of Hibiscus rosa-sinensis. J Pharm Res 2009; 2: 1220-1222.

8. Mandade RJ, Sreenivas SA, Sakarkar DM, Choudhury A. Pharmacological effects of aqueous-ethanolic extract of Hibiscus rosa-sinensis on volume and acidity of stimulated gastric secretion. Asian Pac J Trop Med 2011; 4: 883-888, doi: 10.1016/S1995-7645(11)60213-7.

9. Uddin B, Hossan T, Paul S, Ahmed T, Nahar T, Ahmed S. Antibacterial activity of the ethanol extracts of Hibiscus rosasinensis leaves and flowers against clinical isolates of bacteria. Bangladesh J Life Sci 2010; 22: 65-73.

10. Ruban P, Gajalakshmi K. In vitro antibacterial activity of Hibiscus rosa-sinensis flower extract against human pathogens. Asian Pac J Trop Biomed 2012; 2: 399-403, doi: 10.1016/S2221-1691(12)60064-1.

11. Nath $P$, Yadav AK. Acute and sub-acute oral toxicity assessment of the methanolic extract from leaves of Hibiscus rosa-sinensis L. in mice. $J$ Intercult Ethnopharmacol 2015; 4: 70-73, doi: 10.5455/jice.20141028021746.

12. Al-Snafi AE. Chemical constituents, pharmacological effects and therapeutic importance of Hibiscus rosa-sinensis A review. IOSRPHR J Pharm 2018; 8: 101-119.

13. Missoum A. An update review on Hibiscus rosa-sinensis phytochemistry and medicinal uses. J Ayu Herb Med 2018; 4: 135-146. 
14. Tran TH, Truong THH, Nguyen TTL, Nguyen VMH, Nguyen TMN, Luong TMN. Growth-inhibiting, bactericidal, antibiofilm, and urease inhibitory activities of Hibiscus rosa-sinensis L. flower constituents toward antibiotic sensitive- and resistantstrains of Helicobacter pylori. ACS Omega 2020; 5: 2008020089, doi: 10.1021/acsomega.0c01640.

15. Ngan LTM, Moon JK, Kim JH, Shibamoto T, Ahn YJ. Growthinhibiting effects of Paeonia lactiflora root steam distillate constituents and structurally related compounds on human intestinal bacteria. World J Microbiol Biotechnol 2012; 28: 1575 - 1583, doi: 10.1007/s11274-011-0961-6.

16. Ngan LTM, Moon JK, Shibamoto T, Ahn JY. Growthinhibiting, bactericidal, and urease inhibitory effects of Paeonia lactiflora root constituents and related compounds on antibiotic-susceptible and -resistant strains of Helicobacter pylori. J Agric Food Chem 2012; 60: 9062-9073, doi: 10.1021/jf3035034

17. García-Arata MI, Baquero F, de Rafael L, de Argila CM, Gisbert JP, Bermejo F, et al. Mutations in 23S' rRNA in Helicobacter pylori conferring resistance to erythromycin do not always confer resistance to clarithromycin. Antimicrob Agents Chemother 1999; 43: 374 -376, doi: 10.1128/AAC. 43.2.374.

18. Kim JG, Kim BJ. Antibiotic resistance in Helicobacter pylori infection. Korean J Helicobacter Up Gastrointest Res 2011; 11: 13 - 20, doi: 10.7704/kjhugr.2011.11.1.13.

19. EUCAST. European Committee on Antimicrobial Susceptibility Testing, Breakpoint tables for interpretation of MICs and zone diameters.EUCAST Clinical Breakpoint Table; EUCAST, Version 5.0, 2015.

20. Ali M, Alam P, Singh V, Jameel M, Sultana S. Phytochemical investigations of the leaves and flowers of Hibiscus rosasinensis L. Indian Drugs 2017; 54: 30-37.

21. Salib JY, Daniel EN, Hifnawy MS, Azzam SM, Shaheed IB, Abdel-Latif SM. Polyphenolic compounds from flowers of Hibiscus rosa-sinensis Linn. and their inhibitory effect on alkaline phosphatase enzyme activity in vitro. $Z$ Naturforsch C 2011; 66: 453-459, doi: 10.1515/znc-2011-9-1003.

22. Mangoyi R, Midiwo J, Mukanganyama S. Isolation and characterization of an antifungal compound 5-hydroxy7,4'-dimethoxyflavone from Combretum zeyheri. BMC Complem Altern M 2015; 15: 405, doi: 10.1186/s12906015-0934-7.

23. Santoso BB, Hernandez HP, Rodriguez EB, Dalmacio IF. Two antibacterial compounds: velutin and 4-(hydroxy (oxiran-2-yl) methyl)-2-methoxyphenol from the stem bark of Drimys arfakensis Gibbs. KnE Life Sci 2017; 3: 51-62, doi: 10.18502/kls.v3i5.978.

24. Thawabteh A, Lelario F, Scrano L, Bufo SA, Nowak S, Behrens $M$, et al. Bitterless guaifenesin prodrugs-design, synthesis, characterization, in vitro kinetics, and bitterness studies. Chem Biol Drug Des 2019; 93: 262-271, doi: 10.1111/cbdd.13409.

25. Alavi SHR, Yassa N, Hajiaghaee R, Yekta MM, Ashtiani NR, Ajani $\mathrm{Y}$, et al. Phenolic compounds from Peucedanum ruthenicum M. Bieb. Iran J Pharm Res 2009; 8: 71-75, doi: 10.22037/IJPR.2010.791.

26. Fabry W, Okemo P, Ansorg R. Activity of East African medicinal plants against Helicobacter pylori. Chemotherapy 1996; 42: 315-317, doi: 10.1159/000239460.
27. Bisignano C, Filocamo A, La Camera E, Zummo S, Fera MT, Mandalari G. Antibacterial activities of almond skins on cagA-positive and-negative clinical isolates of Helicobacter pylori. BMC Microbiol 2013; 13: 103, doi: 10.1186/14712180-13-103.

28. Lee HK, Song HE, Lee HB, Kim CS, Koketsu M, Ngan LTM, et al. Growth inhibitory, bactericidal, and morphostructural effects of dehydrocostus lactone from Magnolia sieboldii leaves on antibiotic-susceptible and -resistant strains of Helicobacter pylori. PLoS One 2014; 9: e95530, doi: 10.1371/journal.pone.0095530.

29. Alshami I, Alharbi AE. Hibiscus sabdariffa extract inhibits in vitro biofilm formation capacity of Candida albicans isolated from recurrent urinary tract infections. Asian Pac $J$ Trop Biomed 2014; 4: 104-108, doi: 10.1016/S2221-1691 (14)60217-3.

30. Shoae Hassani AR, Ordouzadeh N, Ghaemi A, Amirmozafari N, Hamdi K, Nazari R. In vitro inhibition of Helicobacter pylori urease with non and semi fermented Camellia sinensis. Indian J Med Microbiol 2009; 27: 30-34.

31. Amin M, Anwar F, Naz F, Mehmood T, Saari N. AntiHelicobacter pylori and urease inhibition activities of some traditional medicinal plants. Molecules 2013; 18: 21352149, doi: 10.3390/molecules18022135.

32. Mabe $\mathrm{K}$, Yamada M, Oguni I, Takahashi T. In vitro and in vivo activities of tea catechins against Helicobacter pylori. Antimicrob Agents Chemother 1999; 43: 1788-1791, doi: 10.1128/AAC.43.7.1788.

33. Cole SP, Kharitonov VF, Guiney DG. Effect of nitric oxide on Helicobacter pylori morphology. J Infect Dis 1999; 180: 1713-1717, doi: 10.1086/315079.

34. Hirukawa S, Sagara H, Kaneto S, Kondo T, Kiga K, Sanada $\mathrm{T}$, et al. Characterization of morphological conversion of Helicobacter pylori under anaerobic conditions. Microbiol Immunol 2018; 62: 221-228, doi: 10.1111/1348-0421.12582.

35. lerardi E, Losurdo G, Mileti A, Paolillo R, Giorgio F, Principi $\mathrm{M}$, et al. The puzzle of coccoid forms of Helicobacter pylori: Beyond basic science. Antibiotics 2020; 9: 293, doi: 10.3390/ antibiotics9060293.

36. Lou Z, Wang H, Rao S, Sun J, Ma C, Li J. p-Coumaric acid kills bacteria through dual damage mechanisms. Food Control 2012; 25: 550-554, doi: 10.1016/j.foodcont.2011. 11.022.

37. Cho JY, Moon JH, Seong KY, Park KH. Antimicrobial activity of 4-hydroxybenzoic acid and trans 4-hydroxycinnamic acid isolated and identified from rice hull. Biosci Biotech Biochem 1998; 62: 2273-2276, doi: 10.1271/bbb.62.2273.

38. Hasan S, Singh K, Danisuddin M, Verma PK, Khan AU. Inhibition of major virulence pathways of Streptococcus mutans by quercitrin and deoxynojirimycin: a synergistic approach of infection control. PLoS One 2014; 9: e91736, doi: 10.1371/journal.pone.0091736.

39. Xiao ZP, Wang XD, Peng ZY, Huang S, Yang P, Li QS, et al. Molecular docking, kinetics study, and structure-activity relationship analysis of quercetin and its analogous as Helicobacter pylori urease inhibitors. J Agric Food Chem 2012; 60: 10572-10577, doi: 10.1021/jf303393n.

40. Abou Baker D. Plants against Helicobacter pylori to combat resistance: An ethnopharmacological review. Biotechnol Rep 2020; 26: e00470, doi: 10.1016/j.btre.2020.e00470. 